\section{Management and Yield Impact of the Greenhouse Whitefly (Trialeurodes vaporariorum) on California Strawberries}

\author{
Gregory J. McKee ${ }^{1}$ \\ Department of Agribusiness and Applied Economics, North Dakota State \\ University, 205-A Morrill Hall, P.O. Box 5636, Fargo, ND 58105
}

Frank G. Zalom ${ }^{2}$

Department of Entomology, University of California, One Shields Ave., Davis, CA 95616

\author{
Rachael E. Goodhue \\ Department of Agricultural and Resource Economics, One Shields Ave., \\ Davis, CA 95616
}

Additional index words. Trialeurodes vaporariorum, Fragaria ×ananassa, imidacloprid, pyriproxyfen, fenpropathrin, malathion, yields

\begin{abstract}
Reductions in strawberry yields were observed in association with infestations of the greenhouse whitefly, Trialeurodes vaporariorum (Westwood). The magnitude of yield impact is estimated using data from a field experiment evaluating nine management approaches for the greenhouse whitefly on strawberries, var. Camarosa. A range of effectiveness and yields was found. Imidacloprid (Admire) applied at transplanting was found to provide the greatest effect on adult whitefly densities. Pyriproxyfen (Esteem) had no immediate effect on adult density but reduced nymphal densities over time. Pairing the use of these products at transplant (Admire) and early spring (Esteem) provided the greatest reduction in whitefly density observed relative to an untreated control. Reductions in strawberry yields were found to increase as whitefly densities grow or as populations persist over time. For example, the estimates from our analysis suggest that at 20 weeks after planting, an average whitefly population may reduce average weekly yields in an untreated field by $\approx 80 \mathrm{~g} / \mathrm{plant}$.
\end{abstract}

The greenhouse whitefly, Trialeurodes vaporariorum (Westwood), is a cosmopolitan pest of greenhouse crops and ornamentals. It damages plants by feeding on nutrients in a plant's phloem, which may result in yield loss (Byrne et al., 1990), and secondarily by its production of honeydew which serves as a

Received for publication 11 July 2006. Accepted for publication 20 Sept. 2006

This research was conducted as part of the thesis submitted by G.J. McKee in the Department of Agricultural and Resource Economics at the University of California, Davis, and was supervised by Rachael Goodhue, Colin Carter, James Chalfant, and Frank Zalom. This research was supported by the Program of Research on the Economics of Invasive Species Management (PREISM), Economic Research Service, U.S. Department of Agriculture, under Cooperative Agreement 43-3AEM3-80081.

The authors thank Pat Thompson for invaluable research support, Husein Ajwa for the use of his strawberry yield data for calibration purposes, and Mark Bolda, Jian $\mathrm{Bi}$, and two anonymous reviewers for valuable feedback on the manuscript. ${ }^{1}$ To whom correspondence should be addressed; e-mail Gregory.mckee@ndsu.edu.

${ }^{2}$ To whom reprint requests should be addressed; e-mailfgzalom@ucdavis.edu.
However, the rate of yield loss associated with greenhouse whitefly feeding on strawberry plants had not been previously quantified.

The objective of this study was to determine the effect of greenhouse whitefly density on strawberry yields. To estimate this, we manipulated field populations by treating with a variety of registered insecticides and measuring the associated yields. The differences in efficacy and associated yields across the selected treatments generated a range of whitefly densities and total yields, enabling a relationship between the two to be estimated. Hereafter we report the methods and results of our study.

\section{Materials and Methods}

The experimental site was a commercial strawberry field located west of Watsonville, Santa Cruz Co., Calif. Strawberries (var. Camarosa) were transplanted into the field on 12 Nov. 2002. This site was located across a paved road and, based on prevailing winds, upwind from infested strawberry plants transplanted in Fall 2001 that had not yet been removed. The new planting was immediately infested by adult whiteflies present in the area.

Three replicates each of nine whitefly management treatments and six replicates of untreated controls were established in a completely randomized design. Each experimental plot was three rows wide, with each row $142.2 \mathrm{~cm}$ wide from center to center, and $50 \mathrm{~m}$ long. The products used in this experiment, formulated rates applied, and their application dates are listed in Table 1.

Products used as experimental treatments included imidacloprid (Admire), pyriproxyfen (Esteem), malathion (Clean Crop Malathion 8-E, Platte Chemical, Greeley, Colo.), a tank mix of fenpropathrin (Danitol) and malathion, and horticultural mineral oil (Omni Supreme Spray, Helena Chemical, Colliersville, Texas). All products were applied at their maximum label rates. Application methods were either in the planting hole (applied in water to the planting hole immediately before transplanting), drip (applied through the drip irrigation line), injected (applied in water solution at the base of the plant after transplanting), and foliar (applied to foliage using an Echo Duster-Mister

Table 1. Experimental treatments applied to strawberries at Watsonville, Calif., 2002-2003.

\begin{tabular}{lclc}
\hline Product & $\begin{array}{c}\text { Rate applied } \\
\left(\mathrm{mL} \cdot \mathrm{ha}^{-1}\right)\end{array}$ & Application method & Date(s) applied \\
\hline Untreated control & $\mathrm{NA}$ & NA & NA \\
Admire then & 2338 & Planting hole & $11 / 12 / 02$ \\
$\quad$ Esteem & 730 & Foliar & $3 / 26 / 03$ \\
Admire & 2338 & Planting hole & $11 / 12 / 02$ \\
Esteem & 730 & Foliar & $3 / 19 / 03$ \\
Malathion & 2338 & Foliar & $3 / 19 / 03$ \\
Admire & 2338 & Drip irrigation & $12 / 2 / 02$ \\
Admire & 2338 & Soil injection & $12 / 13 / 02$ \\
Malathion and Danitol & 2338 and 781 & Foliar & $3 / 19 / 03$ \\
Admire & 2338 & Soil injection & $2 / 27 / 03$ \\
Omni Supreme Spray & $0.50 \% \mathrm{vol} / \mathrm{vol}$ & Foliar & $1 / 30 / 03$ and $3 / 19 / 03$ \\
\hline
\end{tabular}


Air-Assist Sprayer at the equivalent volume of $1870 \mathrm{~mL} \cdot \mathrm{ha}^{-1}$ ).

Whitefly adults in each plot were sampled every three weeks, between 12 Nov. 2002 and 5 June 2003, using the leaf turn method (Naranjo and Flint, 1995). One leaf was sampled at random from three plants within each plot, and all the adults on each leaf were counted. Whitefly nymphs and eggs were sampled every 3 weeks from the start of harvest through 3 July 2003, by selecting and excising three leaves at random from the center row of plants in each plot, placing the leaves into plastic zip lock bags, and returning them to the laboratory where densities per trifoliate leaf were determined under a microscope.

To express the total amount of feeding by a population of whiteflies, we adapted a unit called "whitefly-days" based upon the previously established concept of mite-days (Allen, 1976). The whitefly-days unit represents the quantity of feeding to which a strawberry plant is exposed over time and allows us to statistically test the hypothesis that, as whiteflies continue to feed on a strawberry plant, they cause cumulative damage as both densities increase and the season progresses. The total number of whiteflydays for any sampling period is estimated by the following equation:

$$
\begin{gathered}
\text { whitefly-days }=\begin{array}{c}
\text { no. of days } \\
\text { between } \\
\text { sample dates }
\end{array} \times 1 / 2 \\
\times\left(\begin{array}{cc}
\text { whiteflies per } \\
\text { leaf for } \\
\text { current sample }
\end{array} \quad \begin{array}{c}
\text { whiteflies per } \\
\text { prior sample }
\end{array}\right)
\end{gathered}
$$

Cumulative whitefly-days for any set of sampling periods are calculated as the sum of whitefly-days for all of the sampling periods.

Total whitefly densities, expressed as whitefly-days, were calculated for two periods: 4-13 Dec. (Table 2), which corresponds to the sampling period following treatment and when the invading fall adults were killed by ensuing rain and colder temperatures; and 29 Jan. through mid-June (Table 3), which corresponds to the first observed adults of progeny produced by the invading whiteflies and their successive generations. Because only those plots to which Admire had been applied are relevant during the first period, we report only whitefly-days observations for these treatments in Table 2. All treatments

Table 2. Cumulative whitefly-days per leaf for adults through 13 Dec. 2002.

\begin{tabular}{lc}
\hline Treatment description & Mean \pm SE \\
\hline Untreated & $30.33 \pm 8.26$ \\
Admire at transplanting & $1.20 \pm 0.54^{*}$ \\
Admire at transplanting & $0.60 \pm 0.40^{*}$ \\
$\begin{array}{l}\text { Admire through } \\
\text { drip at } 12 / 2\end{array}$ & $10.50 \pm 2.36$ \\
\hline
\end{tabular}

*Indicates treatment means significantly different at $P<0.05$ from untreated control by Student's $t$ tests.
Table 3. Cumulative whitefly-days per leaf for adults for the period 29 Jan. to 5 June 2003.

\begin{tabular}{lc}
\hline Treatment description & Mean \pm SE \\
\hline Untreated control & $501.50 \pm 74.16$ \\
Admire 12 Nov. 2002, & \\
$\quad$ Esteem 26 Mar. 2003 & $102.10 \pm 4.30^{*}$ \\
Admire 12 Nov. 2002 & $123.65 \pm 34.09^{*}$ \\
Esteem 19 Mar. 2003 & $399.52 \pm 129.00$ \\
Malathion 19 Mar. 2003 & $296.24 \pm 32.19^{*}$ \\
Admire 2 Dec. 2002 (drip) & $122.20 \pm 39.75^{*}$ \\
Admire 13 Dec. 2002 & $275.82 \pm 21.93^{*}$ \\
Malathion and Danitol, & \\
19 Mar. 2003 & $280.02 \pm 66.76^{*}$ \\
Admire 27 Feb. 2003 & $133.70 \pm 8.84^{*}$ \\
Omni Supreme & $371.90 \pm 130.48^{*}$ \\
$\quad$ Spray 30 Jan. 2003, 19 & \\
Mar. 2003 & \\
\hline
\end{tabular}

*Indicates treatment means significantly different at $P<0.05$ from untreated control by Student's $t$ tests. period, and whitefly-days for all treatments listed in Table 1 appear in Table 3.

The numbers and weights of strawberry fruit were determined on six sampling dates: 26 Mar., 17 Apr., 7 May, 29 May, 19 June, and 10 July. No fruit were available for harvest before 26 March. Fruit number and weight measurements were taken every 3 weeks, which is representative of the time a strawberry takes to mature from open flower to ripe fruit. Fruit weight per plant was measured by counting the total number of actual (red) and potential fruit (green and flowers) from 10 plants in the center row of each plot and weighing five randomly selected red fruit to determine the average weight per berry at each sampling date. Yield, in grams per plant, was estimated by multiplying the average number of actual and potential fruit per plant by the average weight of the red berries 3 weeks after the corre- had been applied by the end of the second

sponding sampling date. These data are displayed in summary form in Fig. 1 .

Differences in efficacy of the nine greenhouse whitefly management treatments and measurements of the respective yields from the associated strawberry plants provide a dataset relating cumulative feeding by these individual whitefly populations and resulting strawberry yields. These data enable the use of regression analysis to estimate the incremental effect of whitefly feeding on strawberry yields. Such a regression would express the weekly harvestable yield per plant as a function of time, the number of whiteflydays, and treatment-specific effects.

To simplify the estimation, we make several assumptions about the interactions among strawberry plants, greenhouse whiteflies, and chemical treatments. We assume that the strawberry plant is equally vulnerable to whitefly damage at any point in its developmental cycle, that the effect of whitefly feeding on yield begins upon whitefly arrival, and that Esteem and Admire have no harmful effects on the plant itself. We also abstract from any possible feedback relationship between the health of the plant and the size of the whitefly population; in other words, this analysis measures the direct effect of whitefly feeding on the health of the strawberry plant. Finally, we assume that no viruses are transmitted by the whitefly which might affect yield.

Because our original yield data were gathered at 3-week intervals, they must be converted into weekly periods. To do this, we aggregated yield data from an unrelated experimental plot near our site, planted at the same time as our site, and grown under the same type of mulch, in which strawberry yield data were gathered on a weekly basis. We then assume that the distribution of these yields within the 3 -week period corresponded with the 3-week periods in our study. We then

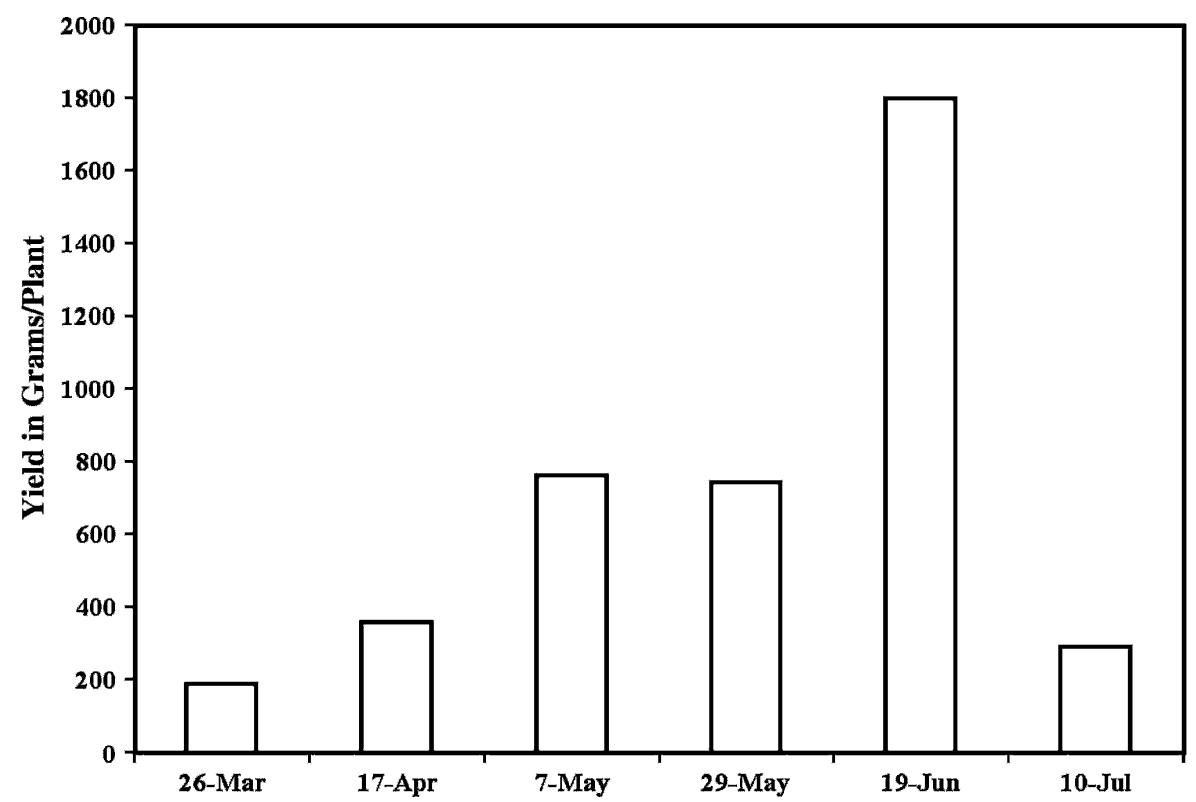

Fig. 1. Average strawberry sample yields (g/plant) across all treatments, by sampling date, Watsonville, Calif., March to July 2003. 
multiplied the observed triweekly yields from our study by the corresponding weekly shares calculated from the unrelated research field.

We estimate a statistical model in which the dependent variable is weekly strawberry harvest, $y_{t}$, where $t$ denotes the number of weeks since planting. Two coefficients are used to test our hypothesis: the cumulative number of adult whitefly-days since the last harvest, $\sum_{j=j-1}^{t} W F_{j}$, and an interaction term multiplying the aggregate number of whiteflydays since the last harvest and the number of weeks since planting, $\left(\sum_{j=j-1}^{t} W F_{j}\right) t$, which measures whether adult whitefly feeding affects yield at different rates over time.

Other variables capture features of the sample data (Fig. 3). Dummy variables $\left(\delta_{i}\right)$ are used to control for differences in yield effects among treatments. We include a time trend that accounts for the number of weeks since planting occurred. A sudden increase in June yield is accounted for with a dummy variable on observations in June, $\delta_{\text {June. }}$ A quadratic time term accounts for sudden changes in the rate of yield produced. A normally distributed error term, $\varepsilon_{t}$, with a zero mean and constant variance is used to represent any other unobserved characteristics of the whitefly-strawberry yield relationship.

\section{Results and Discussion}

Adults from the nearby infested field moved into the study field upon transplanting. The females commenced to oviposit on the undersurfaces of the newly expanded leaves. Figures 2 and 3 present the seasonal development of the adult and nymphal whitefly populations, respectively. Densities of the adults peaked in early Dec. 2002 and then declined as average daily low temperatures observed at a weather station in the Watsonville area declined from $7.24{ }^{\circ} \mathrm{C}$ in Nov. 2002 to $5.56{ }^{\circ} \mathrm{C}$ in Dec., and average daily high temperatures declined from $21.24^{\circ} \mathrm{C}$ in Nov. 2002 to $15.75^{\circ} \mathrm{C}$ in Dec., and due to rain with $8.31 \mathrm{~cm}$ observed at the same weather station in the Watsonville area in Nov. 2002 and $22.56 \mathrm{~cm}$ in December Their eggs and nymphs resulted in the adult peak recorded in late Mar. 2003, and the next generation adult peak which occurred in late May.

Table 2 indicates the total whitefly-days per leaf, through 13 Dec., as modified by treatments applied to the planting hole immediately before transplanting, or through the drip irrigation system about 3 weeks later. The plots in which Admire was applied at transplanting had significantly $(P<0.05)$ fewer whitefly-days than did the untreated control. The Admire treatment applied on 2 Dec. also reduced the number of whiteflydays accumulated during this period, but the difference from the untreated population was not significant.

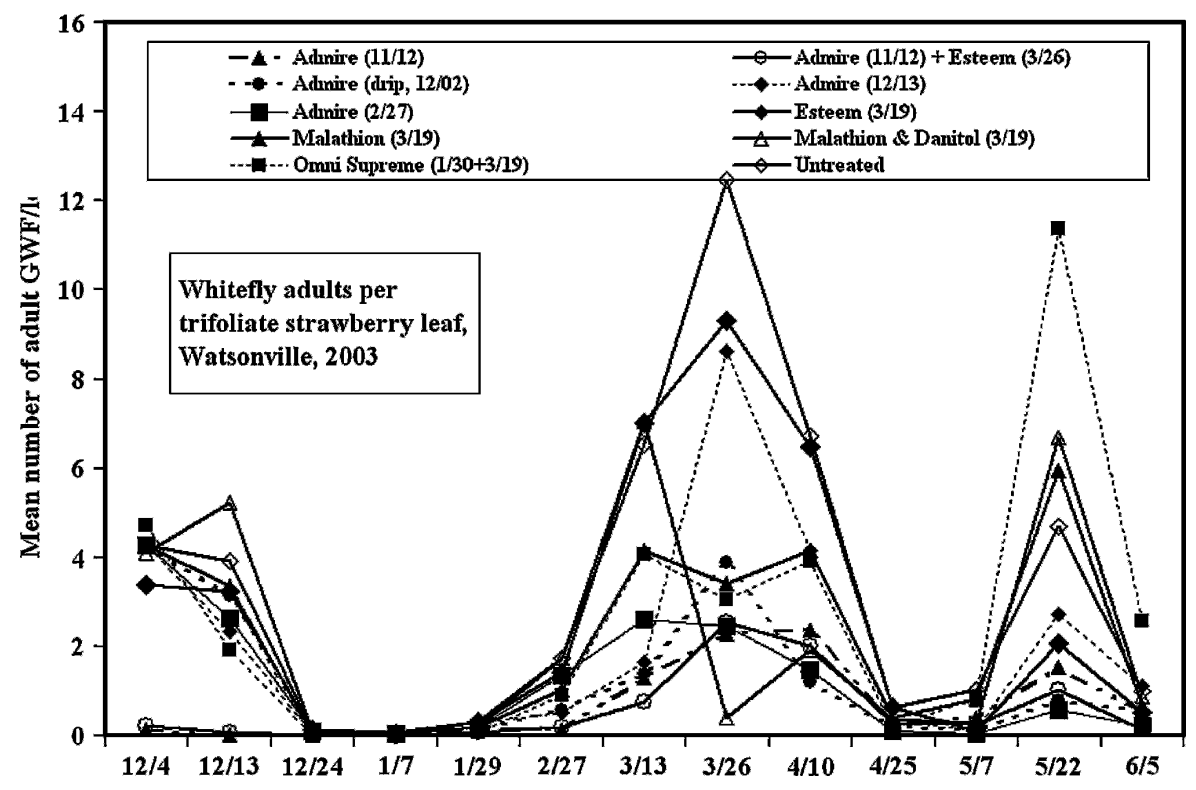

Fig. 2. Average number of adult greenhouse whiteflies per strawberry trifoliate leaf, by treatment and date, Watsonville, Calif., Dec. 2002 to June 2003.

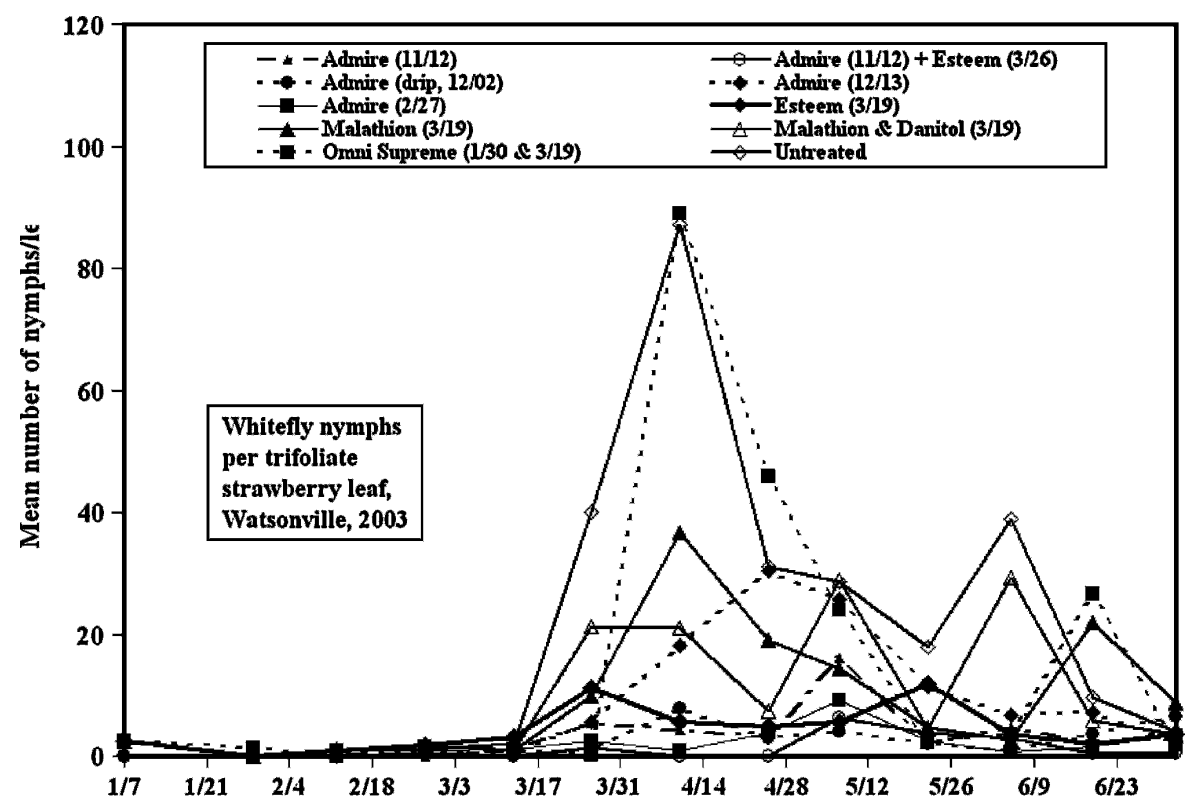

Fig. 3. Average number of greenhouse whitefly nymphs per strawberry trifoliate leaf, by treatment and date, Watsonville, Calif., Jan. to June 2003.

Table 3 indicates the total amount of adult whitefly feeding per leaf, measured in whitefly-days, for all treatments and the untreated controls for 29 Jan. through 5 June, the period after the cold and wet weather killed much of the initial adult immigrant population and including the peak harvest period, reducing the average adult whitefly population from 4.27 adults per leaflet on 3 Dec. 2002 to 0.12 per leaflet on 23 Dec. 2002. All Admire treatments had significantly $(P<0.05)$ fewer whitefly-days than did the untreated controls. The Admire treatment applied on 13 Dec. had over twice as many whitefly-days as those treatments applied at planting or through the drip irrigation system after transplanting, though this difference is not statistically different from other treatments.

As also shown in Table 3, of treatments applied when adult whiteflies began to reappear after the cold and wet weather, the Admire treatment applied $14 \mathrm{~d}$ before the initiation of harvest had a cumulative whitefly-days total comparable to the Admire treatments applied at or near to transplanting. The remaining treatments, all applied 19 or 20 weeks after transplanting (19 or 26 Mar. 2003) had cumulative whitefly-days two to three times higher than the Admire treatment, though not statistically different from other treatments in this sample. We noted that the Esteem-only treatment did not suppress 
adults (Fig. 1) following its application, but it did suppress nymphs (Fig. 2). Therefore, the cumulative whitefly-days based on adult samples for this treatment may be misinterpreted as Esteem being ineffective for whitefly control. These data suggest that an earlier Esteem treatment date, when nymphs are just starting to appear at appreciable densities after the re-emergence of adults in February, might have proven more effective than the later March date. We further noted that all Admire applications except the 13 Dec. treatment had comparable cumulative whitefly-days, suggesting that application of Admire after cold winter temperatures commence will not be as effective, likely because the chemical is not taken up through the roots and translocated by the plant during this time.

Table 4 presents the cumulative nymphal whitefly-days per leaf corresponding to those calculated for adults and presented in Table 3. All treatments significantly reduced the cumulative amount of nymph feeding as expressed in nymphal whitefly-days relative to the untreated controls during the period between 29 Jan. and 5 June except for three treatments for which insufficient data were available. The data in Table 4 show that the treatment combining Admire at transplanting with Esteem in spring had the lowest cumulative nymphal whitefly-days of all treatments. The Admire treatment at transplanting and the late February preharvest Admire treatment resulted in the next lowest cumulative nymphal whitefly-day totals of all treatments. When nymphal whitefly-days are the measure of whitefly feeding, the spring Esteem treatment resulted in the fourth lowest total of all treatments.

While there are a number of approaches to significantly reduce whitefly densities relative to no treatment, our data suggest that the best available insecticide strategies for reducing cumulative feeding by both adults and nymphs includes an Admire treatment at transplanting, or an Admire treatment after the cold winter period and before initiation of harvest.

While the precise mechanics of the interaction between whitefly feeding and straw-

Table 4. Cumulative nymphal whitefly-days per leaf, 29 Jan. to 5 June 2003.

\begin{tabular}{lc}
\hline Description & Mean $\pm \mathrm{SE}$ \\
\hline Untreated control & $3095.60 \pm 760.49$ \\
Admire $11 / 12 / 02$, & \\
$\quad$ Esteem 3/26/03 & $191.44 \pm 56.81^{*}$ \\
Admire $11 / 12 / 02$ & $478.11 \pm 140.61^{*}$ \\
Esteem 3/19/03 & $656.17 \pm 74.61^{*}$ \\
Malathion 3/19/03 & $1274.83 \pm 491.88^{*}$ \\
Admire $12 / 2 / 02$ (drip) & $1336.80 \pm 388.15^{*}$ \\
Admire 12/13/02 & $1336.15 \pm \mathrm{NA}^{\mathrm{z}}$ \\
Malathion and & \\
$\quad$ Danitol 3/19/03 & $1417.28 \pm 472.11^{*}$ \\
Admire 2/27/03 & $302.90 \pm \mathrm{NA}^{\mathrm{z}}$ \\
Omni Supreme & \\
$\quad$ Spray $1 / 30 / 03,3 / 19 / 03$ & $2399.75 \pm \mathrm{NA}^{\mathrm{z}}$ \\
\hline${ }^{\mathrm{z}}$ Insufficient data were available to calculate \\
standard errors for these treatments. \\
*Indicates treatment means significantly different \\
at $P<0.05$ from untreated control by Student's \\
$t$ tests.
\end{tabular}

berry yield are unknown, it is apparent that strawberry yield is adversely affected by the whitefly (Toscano and Zalom, 2003; Udayagiri et al., 2000). We hypothesize that an appropriate way to model the effect of whitefly feeding is to assume that feeding in week $t$ affects yield potential the next week. This is observed through a reduction in the incremental contribution from total yield each harvest. Alternative models were also tested but no statistically significant results were obtained.

We estimate the following model using ordinary least squares.

$$
\begin{aligned}
y t= & \sum_{i=1}^{11} \delta_{i}+t+t^{2}+\beta_{1} \sum_{j=j-1}^{t} W F_{j} \\
& +\beta_{2}\left(\sum_{j=j-1}^{t} W F_{j}\right) t+\delta_{\text {June }}+\varepsilon,
\end{aligned}
$$

where $y_{t}$ is weekly strawberry harvest, dummy variables $\left(\delta_{i}\right)$ represent each treatment, $t$ denotes the number of weeks since planting, $t^{2}$ is the square of this number, $\sum_{j=j-1}^{t} W F_{j}$ represents the cumulative number of adult whitefly-days since the last harvest, $\left(\sum_{j=j-1}^{t} W F_{j}\right) t$ represents an interaction between the aggregate number of whiteflydays since the last harvest and the number of weeks since planting, $\delta_{\text {June }}$ is a dummy for any observation in June, and $\varepsilon_{t}$ is an error term.

Table 5. Parameter estimates for the empirical model of the effect of incremental adult whitefly feeding

\begin{tabular}{|c|c|c|c|c|c|}
\hline & \multicolumn{2}{|c|}{ Coefficient $^{2}$} & & \multicolumn{2}{|c|}{ Coefficient $^{2}$} \\
\hline $\begin{array}{l}\text { Weeks since } \\
\text { planting }\end{array}$ & $\begin{array}{l}t \\
\mathrm{SE}\end{array}$ & $\begin{array}{c}4.854 \\
(1.148)\end{array}$ & Dummy: Esteem 3/19/03 & $\begin{array}{l}\delta_{5} \\
\mathrm{SE}\end{array}$ & $\begin{array}{c}84.200 \\
(30.500)\end{array}$ \\
\hline $\begin{array}{l}\text { (Weeks since } \\
\text { planting) }\end{array}$ & $t^{2}$ & -0.051 & $\begin{array}{l}\text { Dummy: Malathion/ } \\
\text { Danitol 3/19/03 }\end{array}$ & $\delta_{6}$ & 84.161 \\
\hline $\begin{array}{l}\ln \text { (incremental whitefly- } \\
\text { days) }\end{array}$ & $\begin{array}{l}\mathrm{SE} \\
W F_{t}\end{array}$ & $\begin{array}{l}(0.090) \\
52.016\end{array}$ & $\begin{array}{l}\text { Dummy: Admire (drip) } \\
\text { 12/2/02 }\end{array}$ & $\begin{array}{l}\text { SE } \\
\delta_{7}\end{array}$ & $\begin{array}{l}(30.510) \\
84.016\end{array}$ \\
\hline $\begin{array}{l}{[\ln (\text { incremental whitefly- }} \\
\text { days }) \times(\text { weeks since } \\
\text { planting })]\end{array}$ & $\begin{array}{l}\mathrm{SE} \\
\left(W F_{t}\right) t\end{array}$ & $\begin{array}{l}(16.480) \\
-52.070\end{array}$ & $\begin{array}{l}\text { Dummy: Admire } \\
\text { 12/13/02 }\end{array}$ & $\begin{array}{l}\mathrm{SE} \\
\delta_{8}\end{array}$ & $\begin{array}{l}(30.510) \\
84.264\end{array}$ \\
\hline & $\mathrm{SE}$ & $(16.480)$ & & $\mathrm{SE}$ & $(30.510)$ \\
\hline $\begin{array}{l}\text { Dummy: Unti } \\
\text { control }\end{array}$ & $\delta_{1}$ & 84.183 & $\begin{array}{l}\text { Dummy: Malathion } \\
3 / 19 / 03\end{array}$ & $\delta_{9}$ & 84.346 \\
\hline & $\mathrm{SE}$ & $(30.510)$ & & $\mathrm{SE}$ & $(30.490)$ \\
\hline $\begin{array}{l}\text { Dummy: Admire } \\
\text { and Esteem treatment }\end{array}$ & $\begin{array}{l}\delta_{2} \\
\mathrm{SE}\end{array}$ & $\begin{array}{c}84.267 \\
(30.500)\end{array}$ & Dummy: Admire 2/27/03 & $\begin{array}{l}\delta_{10} \\
\mathrm{SE}\end{array}$ & $\begin{array}{c}84.364 \\
(30.500)\end{array}$ \\
\hline $\begin{array}{l}\text { Dummy: Admire at } \\
\text { planting }\end{array}$ & $\delta_{3}$ & 84.260 & $\begin{array}{l}\text { Dummy: Omni } \\
\text { Supreme Spray 1/30/03 \& } \\
3 / 19 / 03\end{array}$ & $\delta_{11}$ & 84.220 \\
\hline $\begin{array}{l}\text { Dummy: Second } \\
\text { untreated control }\end{array}$ & $\begin{array}{l}\delta_{4} \\
\mathrm{SE}\end{array}$ & $\begin{array}{c}84.361 \\
(30.510)\end{array}$ & June Dummy & $\begin{array}{l}\delta_{\text {June }} \\
\mathrm{SE}\end{array}$ & $\begin{array}{l}1.203 \\
(0.067)\end{array}$ \\
\hline
\end{tabular}
on incremental strawberry harvests, Watsonville, Calif., 2002-2003.

${ }^{2}$ Standard errors appear in parentheses. All coefficients are significant at $P<0.05 . \mathrm{N}=182$, Adjusted $R^{2}=0.8736$. The hypothesis of autocorrelation is rejected.

Dependent variable: $\ln ($ incremental harvest, $\mathrm{g} / \mathrm{plant}$ ).
Table 5 reports our findings regarding whether whitefly feeding between two consecutive harvests tends to reduce the subsequent harvest. We found that feeding between harvests generates statistically significant reductions in yield over time. The coefficient on the whitefly-day-weeks crossterm $\left(W F_{t}\right) t$ is negative, indicating that strawberry yield decreases at an increasing rate as whitefly-days increase or time increases. Furthermore, our results indicate that a positive direct effect exists between the size of the whitefly population and harvested yield. We have no empirical interpretation for this result since relatively early declines in yield were actually observed by the grower and authors in the commercial field adjacent to the study plots. These results can be used to estimate incremental reductions in weekly harvestable yield. For example, at 19 weeks (about Mar. 26) after planting and at 149 whitefly-days (which was the average cumulative whitefly-days between Dec. 4 and Mar. 26), the effect of the $\sum_{j=j-1}^{t} W F_{j}$ and $\left(\sum_{j=j-1}^{t} W F_{j}\right) t$ terms is a mean net loss of $\approx 154 \mathrm{~g} /$ plant of yield, resulting in total estimated mean yields of $\approx 84 \mathrm{~g} /$ plant in an untreated plot on that date.

\section{Conclusions}

Our data indicate that greenhouse whitefly feeding reduces yield of fall-planted var. 
Camarosa strawberries in the Watsonville, Calif., area. We find that this rate of yield reduction increases with time and with the size of the whitefly population. Our results indicate that preventative Admire treatment significantly reduces whitefly-days when applied at or soon after transplanting or before harvest commences. Whitefly densities can be significantly reduced by an application of Admire or Esteem targeting the buildup of the early spring population. Our findings are significant for the specific pestcrop relationship we examine and for the modeling of pest-crop relationships more generally. Further, our measurement of the relative efficacy of registered pesticides is significant to the study of how to manage this new pest-crop. Our results suggest that greenhouse whitefly control efforts should be done in such a way as to reduce the cumulative feeding of the greenhouse whitefly popula- tion over the course of the season rather than choosing application times based on the calendar date or whitefly population count alone. More broadly, this finding suggests that it may be the case that modeling pest populations and crop life cycles jointly may improve prediction of pest-induced yield losses.

\section{Literature Cited}

Allen, J. 1976. A model for predicting citrus rust mite damage on Valencia orange fruit. Environ. Entomol. 5:1083-1088.

Bi, J.L., N.C. Toscano, and G.R. Ballmer. 2002. Seasonal population dynamics of the greenhouse whitefly Trialeurodes vaporariorum (Homoptera: Aleyrodidae) on strawberries in southern California. J. Econ. Entomol. 95:1179-1184.

Byrne, D.N., Jr., T.S. Bellows, and M.P. Parrella. 1990. Whiteflies in agricultural systems, p. 227-261. In: D. Gerling (ed.). Whiteflies: their bionomics, pest status, and management. Intercept, Ltd., Andover, Hants., UK.

California Strawberry Commission. 2003. Request for Section 18 emergency exemption. Unpublished, Watsonville, Calif.

Naranjo, S.E. and H.M. Flint. 1995. Spatial distribution of adult Bemisia tabaci in cotton and development and validation of fixed-precision sequential sampling plans for estimating population density. Environ. Entomol. 24: 261-270.

Toscano, N., and F. Zalom. 2003. Management of greenhouse whiteflies. Strawberry News Bull., California Strawberry Commission, Watsonville, Calif., Sept. 2003.

Udayagiri, S., F.G. Zalom, and N.C. Toscano. 2000. The greenhouse whitefly, an emerging pest on central coast strawberries. The California Strawberry Commission, Watsonville, Calif., for The Pink Sheet12 Apr. 2000 . 